\title{
A radicalidade entre a criminologia e a filosofia
}

$\mathrm{I}_{\mathrm{p}}^{\mathrm{n}}$ nterrogar o desenvolvimento dos movimentos e tendências críticas em criminologia, desde sempre, deve passar longe do encerramento metodológico ou das categorizações planificadas ideologicamente. Do contrário, a traição a qualquer postura radical já estaria anunciada e exposta desde sempre, não menos que pelo alijamento do esforço em construir, atualizar e profanar conceitos capazes de captar as lutas sociais e políticas que propriamente lhe dariam sentido.

Portanto, possível e necessário arriscar, afinal a radicalidade não nos é dada. Exatamente, para estarmos à altura de tempos urgentes de violências totalizantes múltiplas, é que a criminologia pode fundar seu limiar filosoficamente. Para que tal condição por vir possa se dar, sem antecipação, o peso imprevisível do acontecimento é a inspiração singular ${ }^{1}$. Afinal, mais diretamente, o que haveria de decisivamente contemporâneo e radical, entre uma criminologia e uma filosofia, senão o profundamente impossível e necessário traço de convocação ética que alguma criminologia possa ambicionar? Na fragilidade densa da resistência contra os blocos maciços de sentidos e racionalidades criminológicas bem pensantes, frente às tendências justificantes de todos os matizes na imposição violenta de supostos fins "justos", talvez (como experiência do possível como impossível ${ }^{2}$ ) ainda reste deixar pulsar instantes outros que excedam toda a presença de um tempo ensimesmado.

Fazer criminologia como se memória política fosse, fantasmagoria criminológica dos sistemas penais, como desajuste radical diante dos fantasmas dos já mortos, dos que ainda não nasceram, vítimas ou não das guerras, dos extermínios e das violências do sistema penal. A bom rigor, a radicalidade filosófica de qualquer criminologia parece não poder distar da interrogação sempre candente sobre o aquilo que pode assumir o sentido de humano - e para além dele - engolido pelas engrenagens criminais/criminosas bem pensadas e objetificantes de um estado de coisas que não se suporta mais, senão ao preço das suas maiores perversões, ser conciliado e sustentado como normal.

O que mais deverá ser recorrente e inesgotável num discurso criminológico radical senão a incisividade no convite à monumental evocação sobre os restos transparentes da história esquecidos pela máquina penalizante? Espectros de palavras que reverberam propriamente sobre aquilo que por elas não é alcançado: o testemunho sobre a dor do outro, limite absoluto da minha representação ${ }^{3}$, que teoria nenhuma será capaz de lhe fazer justiça. Uma estirpe criminológica tocada por uma ética da vida, do qual todo o mais é derivado, será campo assombrado que haverá de aprender a viver com fantasmas ${ }^{4}$ - aventura estranha e desconfortável que não substitui o que se viveu e morreu pela memória do acontecido, nem está centrada na ideia do que se passará (pois não a temos), entretanto que urge pela representação não solitária e indeterminável do outro que habita clandestinamente toda a lógica (criminológica) exaurida. Pro-vocação inaudita de uma responsabilidade radical

${ }^{1}$ DERRIDA, Jacques. Uma certa possibilidade impossível de dizer o acontecimento. Tradução de Piero Eyben. In: Revista Cerrados (Revista do Programa de Pós-Graduação em Literatura da UnB), Brasília, v. 21, n. 33, p. 228-251, 2012.

2 DERRIDA, Jacques. Como se fosse possível, “within such limits"... In: Papel-máquina. Trad. Evandro Nascimento. São Paulo: Estação Liberdade, 2004, p. 258-259.

3 ADORNO, Theodor W.. Dialética negativa. Tradução de Marco Antonio Casanova. Rio de Janeiro: Zahar, 2009, p. 173.

${ }^{4}$ Estamos às voltas, notadamente, do precioso "Exórdio" de DERRIDA, Jacques. Espectros de Marx: o estado da dívida, o trabalho do luto e a nova Internacional. Tradução de Anamaria Skinner. Rio de Janeiro: Relume-Dumará, 1994, p. 09-13. 
que algum discurso criminológica não poderá olvidar. Questão de justiça, pois. Algo que talvez uma im-possível criminologia - e não falamos aqui do direito ou da sua ciência correlata diretamente - possa recorrer como herança ética de um desajuste, da dia-cronia irredutível da alteridade. Expressa assim tal desejo Derrida, rico agora também para uma sintonia radical criminológica sem vacilações:

Justiça alguma - não digamos lei alguma, e mais uma vez lembro que não falamos aqui do direito parece possível ou pensável sem o princípio de alguma responsabilidade, para além de todo presente vivo, nisto que desajusta o presente vivo, diante dos fantasmas daqueles que já estão mortos ou ainda não nasceram, vítimas ou não das guerras, das violências políticas ou outras, dos extermínios nacionalistas, racistas, colonialistas, sexistas ou outros, das opressões do imperialismo capitalista ou de todas as formas do totalitarismo. Sem essa não contemporaneidade a si do presente vivo, sem isto que secretamente o desajusta, sem essa responsabilidade e respeito pela justiça com relação a esses que não estão presentes, que não estão mais ou ainda não estão presentes e vivos, que sentido teria formular-se a pergunta 'onde?', 'onde amanhã?' ('whither?'). ${ }^{5}$

Onde, amanhã, uma criminologia radical? Se fosse possível dizê-la, o polo atrator haveria de tocar uma criminologia pela desconstrução - "justiça como núcleo indesconstruível de toda a desconstrução" - , que inédita ela apenas poderia dizer-se se seu próprio discurso já não tivesse flertado com o mero dito - encadeamento lógico de enunciados - e não procedesse literalmente de um tempo por vir.

Se a desconstrução deve enxergar a partição no coração dos conceitos, desde sempre carregará o criminólogo, tal como o filósofo, o coração partido como sua marca genética diante do limiar entre a filosofia e a criminologia. Interditados à totalidade, o filósofo aqui encontra o criminólogo em seu amor pelo mundo, devendo suportar estar diante do trauma que é a desconstrução do próprio mundo, da precariedade de sentidos e da espectralidade do real, e estar sempre disposto a denunciar toda e qualquer postura autoritária que tente apresentar o mundo em sua plenitude - o real em sua violenta totalização - espantando assim o assombro originário que é o que inaugura a própria filosofia. Conectivo "e" que impinge ao insubstituível "mais de um" e denuncia o umbral como solidez fundadora, limite entre o dentro e o fora da própria inclusão e exclusão reclamando-nos uma perene vigilância a respeito das absolutizações, do solo único da uma linha indivisível. Criminologia e Filosofia tornam-se nesta decisão, convite de desconstrução para além da alternativa entre continuidades e cisuras, o que, mais do que um solo firme, possa permitir lançarmo-nos para um único plural além de si.

Axioma pronto, por assim dizer, a desestabilizar (inclusive) os esquemas conceituais (críticos) e destotalizar totalidades autorreferentes. A desconstrução ${ }^{7}$, se é que isto possa se dar, busca traços a partir destes ecos singulares que as racionalidades tão bem sabem governar. Haveria uma criminologia filosoficamente não domesticada, neste enfoque, naquilo que estivesse preocupada com as intempestividades que ocupam o nosso presente, o que significa em termos dos aparatos maquínicos do poder penal, colocá-lo face a si mesmo, decompor a estrutura e entender como havia sido construído seu conjunto, não meramente como denúncia, mas como trauma assimétrico a qualquer forma de adaptação. O interesse está, para além de qualquer método,

\footnotetext{
5 DERRIDA, Jacques. Espectros de Marx, p. 11-12.

${ }^{6}$ DERRIDA, Jacques. Force de Loi: Fondement Mystique de 1'Autorité. Translated by Mary Quaintance. In: Cardozo Law Review, New York, v. 11, n. 5-6, p. 919-1045 (cit. p. 944), July/Aug. 1990,

7 "A desconstrução, evidentemente, podemos considerar que consiste justamente em colocar os ladrilhos do avesso, enfim, perturbar uma ordem. DERRIDA, Jacques. Rastro e arquivo, imagem e arte. Diálogo. In: MASÓ, Joana; MICHAUD, Ginette; BASSAS, Javier (Org.). Pensar em não ver: escritos sobre as artes do visível. Tradução de Marcelo Jacques de Moraes. Florianópolis: Ed. da UFSC, 2012, p. 138.
} 
por aquilo que, historicamente se institui como ordem, como sistema penal, na qual uma desordem violenta foi chancelada e fixada com normalidade.

Compromisso com o que virá, precedido e ancorado naquilo que não é ainda, com o que vem sem ser visto, estratagema afeto, não obstante, a um aqui agora sem reenvio infinito, uma injunção democrática a rigor que não se pode deixar idealizar, pois é na vida com todo o seu peso e concretude vinda de cima, inegavelmente real e sensível, que um im-possível por vir confia ${ }^{8}$. Incomensuravelmente humana tal Criminologia em sofrimento, que resta, limiar, neste traço disjuntivo posto como lembrança entre os conceitos - heterogêneos mas indissociáveis - de direito e de justiça.

Uma criminologia radical, inadequada por excelência e desajeitada em algum desajuntamento sobre o qual sempre se perguntará “onde amanhã?” (whither?) -, assombrados por espectros de vidas vividas jamais neutralizáveis, "experiência do passado como porvir, um e outro absolutamente absolutos, para além de toda a modificação de um presente qualquer", ou seja, criminologia diante daquilo que vem sempre antes dela como origem: "experiência do passado como porvir". Experiência justamente não como relação presente, mas como viagem ou travessia, um experimentar que remete a algo não programável, exposto ao acontecimento do outro, radicalmente outro, inapropriável que faz prova de sua alteridade exatamente por este fato ${ }^{10}$.

A questão sobre uma criminologia que assim nos abate já não deixa de transparecer na tradição do seu conceito outro sentido que não a da escritura de uma ausência, silêncio próprio dos corpos emudecidos e empilhados pelas inscrições cadavéricas politicamente neutras. Não somente a escuta criminológica sobre "a palavra dos mortos" pode-se dar neste instante aberto $^{11}$, porque o que apareceria neste momento espectral já não pertence a este tempo, mas o secreto desajuste estaria assinalado pela resposta - testemunho radical - premente aos que não estão aqui presentemente vivos, seja porque não mais estejam presentes e vivos, mas fundamentalmente pelos que ainda não estão presentes. O cuidado em si de qualquer cautelaridade nos (re)envia a este futuro, nada distanciado ou indefinido, mas sobretudo a tarefas inadiáveis, noção que um discurso criminológico radical deve-se (ante)ver. O que nos convoca, então, dá-se antes - provém do porvir, do futuro que já eticamente nos sequestrou e desproporcionalmente nos impõe em seu excesso a responsabilidade urgente por um dever de justiça. Supõe-se que este justiça conduza, não meramente "para com a vida de um ser vivo (...) não em direção a uma morte, mas em direção a uma sobre-vida" ${ }^{12}$, reiteradamente para além da vida presente, que antecipa que é preciso contar com mais de um. Criminologias plurais como dizeres de uma sobre-vivência, apanhadas pelo aqui e agora impostergáveis do terror que as apanha e sempre anacrônicas em suas tentativas de organizar-se e definir-se. Reinscrever o incondicional ética da justiça sob certas condições parece tocar aporeticamente a tarefa impossível de se viver sob o status meramente político ou legal de qualquer criminologia radical, não obstante sempre obrigada, de outro modo, a dispor-se decididamente diante da incondicionalidade da alteridade, expor-se efetivamente de certo modo condicionada, sob pena de sequer a ideia tardia e ancestral do outro poder ser reinscrita. Concretamente, dizer-o-acontecimento indizível (para além do simples saber e da informação) que tem lugar ali onde se põe como chance do próprio possível, razão que apenas se deixa razoar porque conta com e toma em conta os mortos da guerra neutralizada racionalmente pelo poder punitivo, escuta dos "espectros de um experiência impossível que assombra o possível”’3.

\footnotetext{
${ }^{8}$ DERRIDA, Jacques. Vadios: Dois Ensaios Sobre a Razão. Coordenação, Tradução e Notas de Fernanda Bernardo. Coimbra: Palimage, 2003, p. $155-178$.

9 DERRIDA, Jacques. Espectros de Marx, p. 12

${ }^{10}$ DERRIDA, Jacques. Pensar em não ver. In: Pensar em não ver: escritos sobre as artes do visível, p. 80.

${ }^{11}$ ZAFFARONI, Eugenio Raul. La palabra de los muertos: Conferencias de criminologia cautelar. Buenos Aires: Ediar, 2011, p. 01-19.

12 DERRIDA, Jacques. Espectros de Marx, p. 13.

${ }^{13}$ DERRIDA, Jacques. Uma certa possibilidade impossível de dizer o acontecimento, p. 238 e 242. Particularmente destacado em DERRIDA, Jacques. Vadios, p. 259 ss..
} 
É possível conservar a oportunidade de capturar o inaudível? Contador e responsável por aquilo que não se tem e que não nos pertence? A sorte deste acontecimento é a sorte de um instante ${ }^{14}$. Por fim, aí a tarefa se inicia. Talvez seja neste umbral, aqui surpreendido na íntima correlação entre violência e direito que alguma criminologia fundada filosoficamente possa começar enfim. Pensamento desconstrutivo - racionalismo incondicional que jamais renuncia a suspender todas as condições inclusive aquelas que fundam a própria ideia de crítica - aqui posto sobre o poder soberano (penal), precisamente debruçado neste limite indivisível e que, ao mesmo tempo, ameaça não somente esta condição, mas sua própria solidez fundadora. Há "mais de um único único" 15 , dirá Derrida novamente, ao permanentemente interrogar tal limiar, contudo o passo arriscado que se reclama é ao abismo, que não mais pode ser nem fundamento original ou fundo nem a profundidade mesma sem fundo. Do contrário, de toda forma, renunciar a essa experiência impossível da alteridade - pro-vinda das vozes que, em surdina, grunh(iram)em abafadas pelos empolados discursos prontos a salvar a reta consciência punitiva (ou negociar com as consolações do presente) - sem horizonte de espera e momento de justiça espectral com certos outros não presentes, para além do presente vivo em geral, todavia concreto e radical, sem este justa abertura criminológica, melhor e por certo mais honesto, seria render-se ao "calculismo econômico", aos utilitarismos com cálculo de rentabilidade (positivismos criminológicos, diga-se de passagem), à biopolítica em geral, e declarar todas as "barreiras alfandegárias" a estas criminologias menores, esteriotipadas, "sem modos", mal-educadas (infantis dirão os cínicos), comprometidas com a "modalidade futura do presente vivo", teimosas e indóceis a sobre-viverem insuscetíveis às reduções pragmáticas de contingências políticas (re)confortantes e conciliações hipócritas ${ }^{16}$. Apesar do insuportável, encarnam-se os espíritos dos mortos de dos vivos nesta insaciável necessidade por justiça, radical será aquela sobre-vivente criminologia que se puser a ensinar a escutá-los.

O presente número de Sistema Penal \& Violência traz tanto no Dossiê Criminologia E Filosofia quanto nos demais artigos inseridos na linha de pesquisa ViolÊNCIA, CRIME E SEGURANÇA PúBLICA este exercício de escuta. Cada texto, a seu modo, apresenta sua dose de inspiração. O espaço intersticial propiciado combina dinâmicas de diversas tonalidades e dispara em diferentes direções. Se Leandro Ayres França explora o paradigma imunitário, montado por Roberto Esposito, explicando a ativação e as renovações da biopolítica na atualidade, será Fernanda Martins a pontuar, na esfera da crítica da deslegitimação do poder punitivo, particularmente o papel dos discursos da Revista de Direito Penal e Criminologia. Quando Fábio Gomes de França embrenha-se na crítica foucaultiana à defesa social estampada nas escolas clássica e positiva para analisar a gênese do indivíduo perigoso, o aporte crítico não cessa, tendo o estudo sobre a violência e a antropotécnica, desde o pensamento de Peter Sloterdidijk apresentado por David Leal da Silva e Ricardo Gloeckner Jacobsen, o esforço de apontar ainda importantes técnicas de domesticação e produção humanas na atualidade.

Anelise Schütz Dias e Isabel Padilha Guimarães, por sua vez, investem na tormentosa e importantíssima questão acerca das construções sociais na combinação violência, crime e mídia, problematizando especialmente esta última como agência do sistema penal capaz de mover os discursos de violência. Segue-se o sopro da crítica de Alexandre Pandolfo com sua expressão ensaística da angústia conformadora do estado de exceção. Na mesma fenda movediça da contiguidade entre violência e direito então mobilizada é que Augusto Jobim do Amaral fará a incursão privilegiada sobre o ponto cego da soberania guardado no espectro policial.

\footnotetext{
${ }^{14}$ DERRIDA, Jacques. As Pupilas da Universidade: o Princípio da Razão e a Ideia da Universidade. In: O Olho da Universidade. Introdução de Michel Peterson e tradução de Ricardo Canko et. al.. São Paulo: Estação Liberdade, 1999, p. 156-157.

${ }^{15}$ DERRIDA, Jacques. Seminario La bestia y el soberano. Volumen I (2001-2002). Edicción establecida por Michel Lisse, Marie-Louise Mallet y Ginette Michaud. Buenos Aires: Manantial, 2010, p. 362 e 388.

${ }^{16}$ Cf. DERRIDA, Jacques. Espectros de Marx, p. 92-3.
} 
Manuela Abath Valença e Helena Rocha Coutinho de Castro cuidam de investigar na aplicação das medidas socioeducativas a formação das ontologias criminosas dos usuários de drogas ilícitas, desde a fundamentação das decisões judiciais. Em sentido estrutural análogo, o estudo de Beatriz Gershenson Aguinsky, Guilherme Gomes Ferreira e Marcelli Cipriani atravessa os embates do sistema penal face aos travestis e transexuais, expondo a precarização e vulnerabilidade a que são expostos tais grupos diante das agências de criminalização. O trato rigoroso e incisivo do sistema punitivo continua no texto de Ranulfo Paranhos, Dalson Britto Figueiredo Filho, José Alexandre da Silva Jr. e Enivaldo Carvalho da Rocha, agora focado no encarceramento feminino, estabelecendo quais os mecanismos seletivos que operam para a formação do contingente de mulheres encarceradas no Brasil.

A vida nua e o estado de exceção, problemáticas que pairam como pano de fundo mais ou menos intensamente dispostos nas diversas reflexões, é também retomado diretamente por Gustavo Oliveira de Lima Pereira no cenário das relações internacionais apondo a crítica biopolítica ao capitalismo atual. Tais espaços de exceção contemporâneos são alçados sob diferentes tons quando Bruno Silveira Rigon, Juliano Carvalho e Gabriel Divan tratam de iluminá-los desde o papel do testemunho, visto como instrumento fundamental de elaboração do trauma e de não repetição da barbárie. Por fim, Gustavo Covolan Bozzetti e Rosa Maria Zaia Borges é que situam precisamente o conceito de responsabilidade de proteger em âmbito internacional como sintomático mecanismo retórico nas decisões de intervenção e desrespeito dos direitos humanos.

Abrem-se, enfim, registros de escrita plurais, caminhos cruzados que concretamente dispõem sobre o desafio permanente de transformar a crise - falsamente posta como normalidade alheia ao tempo - naquilo que efetivamente ela é: instante de julgamento e decisão, com toda a carga de responsabilidade ética que isso implica. Que da criminologia não seja abolida esta ligação.

AUGUSTO JOBIM DO AMARAL Doutor em Altos Estudos Contemporâneos (Ciência Política, História das Ideias e Estudos Internacionais Comparativos) pela Universidade de Coimbra, Portugal. Doutor, Mestre e Especialista em Ciências Criminais pela PUCRS. Professor da Faculdade de Direito da PUCRS 